\title{
The situation and typical model of mine environment restoration and treatment in Su Hu Area based on Remote Sensing Technology
}

\author{
Li Li ${ }^{1, *}$, Wang Haiqing ${ }^{l}$, Wang Jie ${ }^{l}$, Yin Yaqiu ${ }^{l}$, Liu Xiaoyang ${ }^{l}$ \\ ${ }^{1}$ China Aero Geophysical Survey \& Remote Sensing Center for Nature Resources, Beijing 100083, China
}

\begin{abstract}
With the increasing development and utilization of mines in China, the economic development is accompanied by the destruction of the geological environment of mines. The state vigorously promotes the construction of ecological civilization, and the restoration and treatment of mine environment has become increasingly important. Based on remote sensing technology and high-resolution remote sensing image, this paper investigates the situation of mine environment restoration and treatment in $\mathrm{Su} \mathrm{Hu}$ area, and discusses typical cases of mine environment restoration and treatment, so as to provide reference for mine restoration and treatment.
\end{abstract}

\section{Introduction}

Under the guidance of the concept that "green water and green mountains are the golden mountains and silver mountains", the restoration and treatment of the geological environment of mines in $\mathrm{Su} \mathrm{Hu}$ area has been strengthened ${ }^{[1]}$.As a new and convenient information acquisition technology, remote sensing technology can provide regional periodic information, and can carry out large-scale synchronous monitoring, with large information coverage. Using remote sensing technology can obtain the relevant information of mine environmental restoration and treatment, and the amount of data obtained by remote sensing is large and the data can be updated quickly, which can monitor the mine environmental restoration and treatment in real time and update the data in time. In this paper, remote sensing technology is used to extract information and analyze the situation of mine recovery and treatment comprehensively in the study area, so as to summarize relevant treatment experience for mine geological environment recovery and treatment. ${ }^{[2]}$

\section{Overview of the research area}

The survey area covers 122 county administrative regions in two provinces (cities) of Jiangsu and Shanghai. Jiangsu is located in the central part of the eastern coastal area of China, the lower reaches of the Yangtze River and Huai River which span $116^{\circ} 18^{\prime}-121^{\circ} 57^{\prime}$ and $30^{\circ} 45^{\prime}-35^{\circ} 20^{\prime}$, with the $3383 \mathrm{~km}$ inter provincial land margin, covering 107 thousand and $200 \mathrm{~km}^{2}$, about $1.12 \%$ of the whole country ${ }^{[3]}$. Shanghai is located between $120^{\circ} 52^{\prime}-122^{\circ} 12^{\prime} \mathrm{E}$ and $30^{\circ} 40^{\prime}-31^{\circ} 53^{\prime} \mathrm{N}$, on the west coast of the Pacific Ocean and the east coast of the
Asian continent, the center of the South and north coasts of China, the junction of the Yangtze River and the Huangpu River, covering an area of about $8400 \mathrm{~km}^{2}$, bordering the Yangtze River in the north, the East China Sea in the East, Hangzhou Bay in the south, Jiangsu Province and Zhejiang Province in the West. ${ }^{[4]}$

\section{Data source}

The survey adopts the 2017 remote sensing image data, and the imaging time is from August 2017 to December 2017.Data types include GF1,GF2,BJ2,ZY3, etc., data coverage $100 \%$, data resolution of $0.5 \mathrm{~m}-2 \mathrm{~m}$, mainly $1 \mathrm{~m}$. The overall data quality is good, basically no distortion, no strip, less cloud, and the mine features can be easily identified, the data meets work requirements.

\section{Information extraction method}

The interpretation work is carried out on Acrgis. According to the established remote sensing image interpretation signs, combined with the previous survey data of the survey area and a large number of auxiliary data such as topography, vegetation,soil,etc.,various interpretation methods are comprehensively used to supplement and modify the mine development information.

Information extraction is carried out under the condition of full resolution of the image, the minimum spot of information extraction is $4 \mathrm{~mm}^{2}$, and the accuracy of information extraction is within 2 pixels.

For any doubted interpretation information, it is necessary to fill in the remote sensing monitoring interpretation and field record form of mineral resources development, and implement self-inspection and mutual

\footnotetext{
* Corresponding author: dairywoman@126.com
} 
inspection system in the interpretation process to ensure the accuracy of interpretation results. ${ }^{[5]}$

\section{General situation of mine recovery and treatment in the working area}

In the annual remote sensing survey of 2017, it was found that the area of mine restoration and control in Jiangsu Province was 12741.85 ha, and the percentage of restoration was $32.14 \%$. The total area of mine treatment project in Shanghai is $57.82 \mathrm{ha}$, the percentage of which is $43.63 \%$.

Suzhou, Suqian, Nantong, Nanjing and Changzhou are the top five cities in terms of the proportion of the restoration area. The recovery area of Suzhou is $368.68 \mathrm{ha}, 65.45 \%$, Suqian is $824.69 \mathrm{ha}, 58.10 \%$, Nantong is $616.34 \mathrm{ha}, 44.78 \%$. The restoration area of Nanjing is 2304.26 ha, accounting for $42.89 \%$ of the total area of mining activities in 2017; the restoration area of Changzhou is $968.37 \mathrm{ha}$, accounting for $35.6 \%$ of the total area of mining activities in 2017.Xuzhou has the largest restoration area, followed by Nanjing and Zhenjiang, with 3322.33ha, 2304.26ha and 1293.8ha respectively, accounting for $54.31 \%$ of the total restoration area. Due to the imbalance of local economic development, the current situation of mineral resources development and utilization, and the difference of mine environmental geological problems, the area and rate of recovery and treatment of damaged land occupied by mines in different cities of the working area are unbalanced.

\section{Typical restoration and treatment works}

Both Jiangsu and Shanghai attach great importance to the restoration and treatment of the mine ecological environment. Taking the environmental protection and treatment of open cut ore mine as a breakthrough, they actively promote the environmental protection and treatment of mines, focusing on the overall development, highlighting the key points and accelerating the promotion.

\subsection{Recovery and treatment of strip pit}

Fig. 1 is the image and field photo of an open pit mine in Jiangsu Province after restoration and treatment. The main ore type of the mine is sandstone, and the excavation pit is located between two hills. The mining face forms a scarp, and the accumulation of solid waste is easy to cause geological disasters. After field verification, most of the stopes of the mine have been recovered and treated. In order to prevent geological disasters such as landslide and debris flow in the mining area, slope protection has been carried out on the west side of the mining face, and the north side of the mining face has been leveled into 8 steps with green plants planted on the steps.

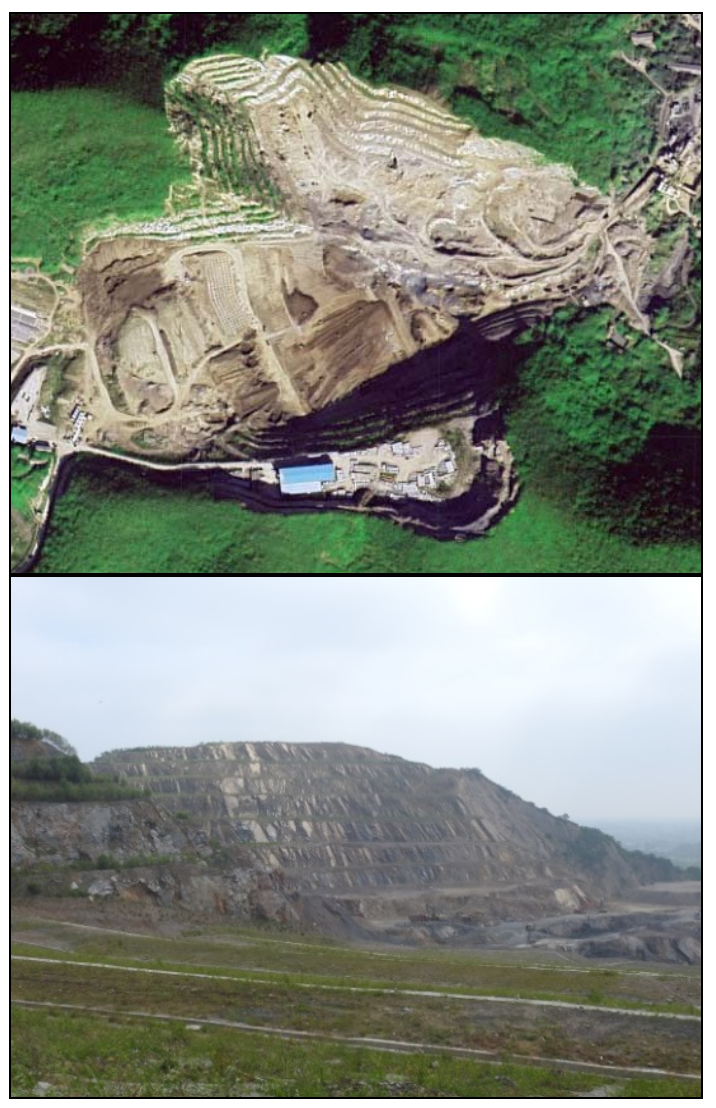

Fig.1. Image and site photo of a quarry in Jiangsu after restoration (image data source: BJ2)

\subsection{Reclamation of abandoned building placer}

Fig.2 is the remote sensing image and field photo of a building placer reclaimed in Yizheng City. This is a government land reclamation project of mine. After the stope of mining, the mine has been leveled, and the land is covered by loess ,it is suitable for plant growth with the advantage of flat terrain. 


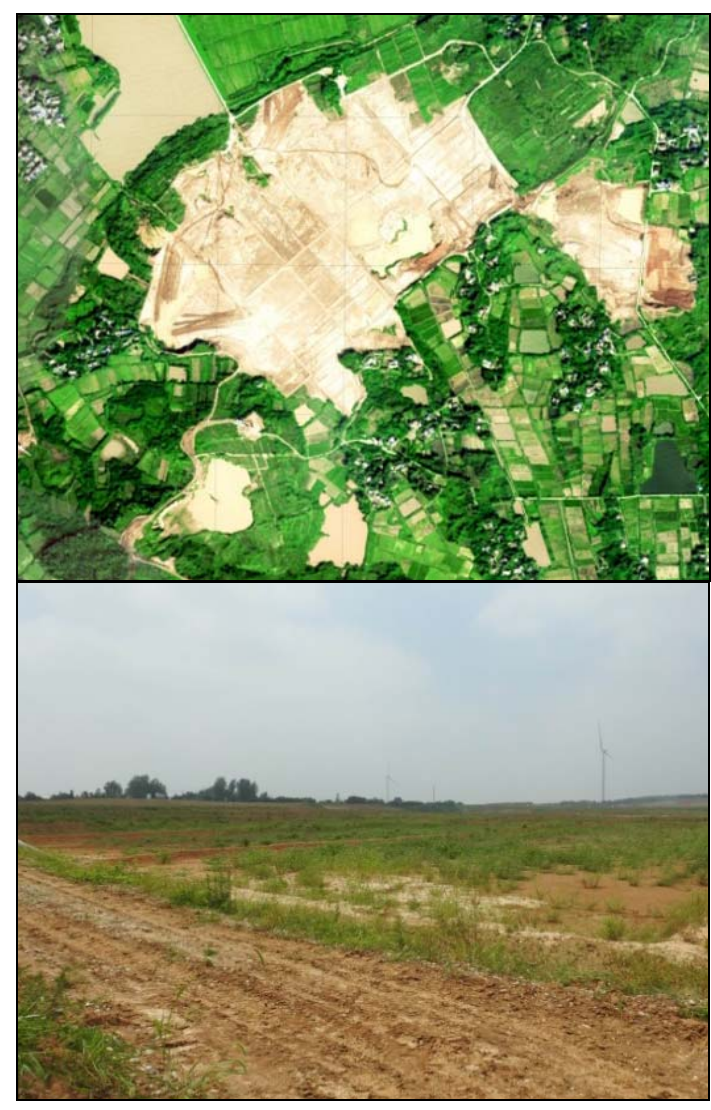

Fig.2. Image and site photo after restoration and treatment of open-pit construction Placer in Yizheng City (image data source: BJ2)

\subsection{Recovery and treatment of subsidence pit in underground mining coal mine}

The treatment modes of subsidence pit: aquiculture mode in the deep subsidence area of multi-layer coal mining, cultivation mode in the shallow subsidence area, reclamation mode in the subsidence area filled with coal gangue for infrastructure relocation, reclamation mode in the subsidence area filled with fly ash for building artificial forest, mixed cultivation of fish and duck in the subsidence area with deep and shallow intersection, reclamation mode in the fruit and vegetable intercropping, use the large subsidence area as the fishpond and the water park to rebuild ecological environment of the mining area. The specific measures include management of water area in subsidence area, gangue filling, loess backfilling, road hardening and tiling, tree planting, slope protection, trestle construction, etc.

Fig.3 is the image and field photo of collapse pit restoration and treatment, the subsidence is caused by the production of an underground mining coal mine in Xuzhou City. Some of the subsidence pits in the mine have been comprehensively developed in agriculture, and developed into lotus pond, fish and duck breeding, etc., by taking advantage of the water accumulation and climate environment in the south.The long-standing and gradually stable subsidence pit has been treated as wetland park, etc.

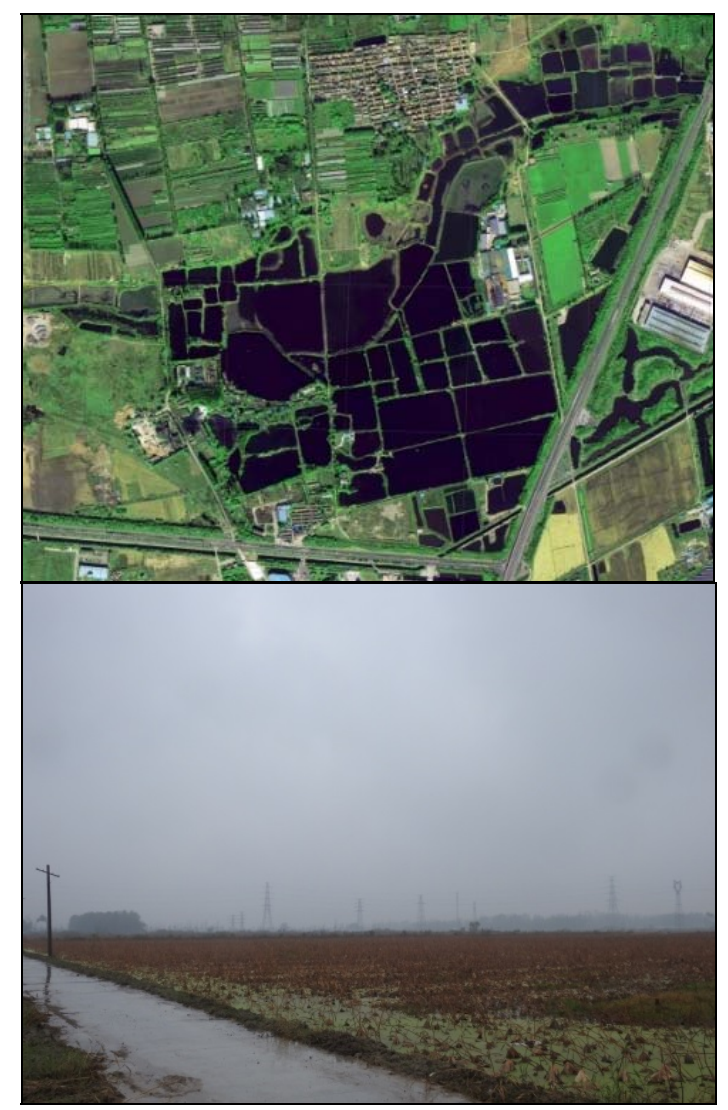

Fig.3. Image and site photo of a coal mine subsidence pit after restoration and treatment (image data source: GF2)

\subsection{Restoration and treatment of clay mine for brick and tile}

Most of the clay mines for bricks and tiles in the working area are located in plain areas, with flat terrain and near the water. The pit formed by mining often has deep water, which accumulates day by day after being abandoned. The ore heap of mine production requires a high degree of ground leveling and less damage to the original components of the soil. Therefore, it is convenient to recover and control the land in the later period. The recovery and control measures of clay mines for bricks and tiles in the working area are generally land reclamation. After removing the ore heap, it will be slightly leveled and planted by rice or landscape turf, as shown in Fig.4. 


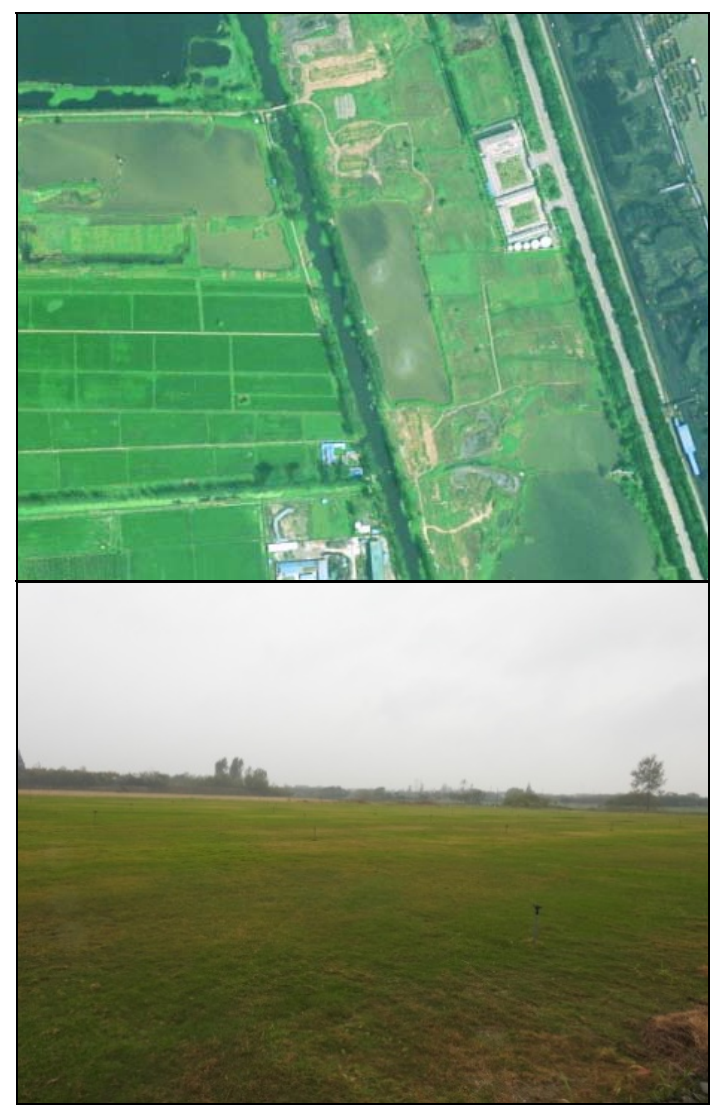

Fig.4. Clay mine for brick and tile after restoration and treatment (image data source: GF2 + BJ2)

\subsection{Recovery and treatment of cement-used limestone}

Cement limestone mines are mostly open-pit mining, or built near mountains or deep pit mining, often forming a steep slope, which poses a potential safety hazard to the production of the mining area. Therefore, many mines carry out recovery treatment at the same time of production, and the mined slope has been treated, as shown in Fig.5. The mine is in production, and some slopes have been treated. It can be seen that the steps are clear, flat and planted with green plants.

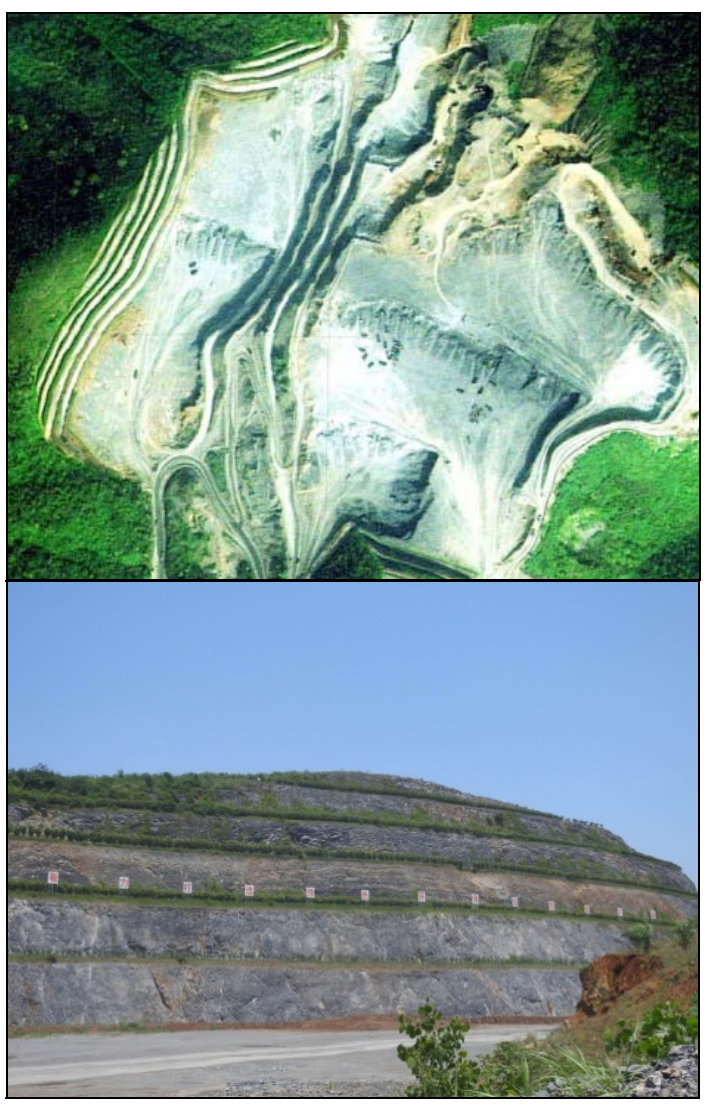

Fig.5. Image of a cement limestone mine in Jiangsu Province and its restoration (image data source: BJ2)

\section{Conclusion}

In this paper, remote sensing technology is used to extract information from the geological environment restoration and treatment of mines in $\mathrm{Su} \mathrm{Hu}$ area, giving full play to the characteristics of remote sensing technology, such as large area, fast access to data, intuitive and objective response to information, saving a lot of costs, and providing accurate and objective data for mastering the recovery and treatment of mines in the whole area. ${ }^{[6]}$

In this paper, the recovery and treatment information of typical mines in the study area is comprehensively studied and analyzed, different treatment methods of different types of mines are summarized, and relevant treatment experience is accumulated, which is of reference and popularization significance in mine recovery and treatment measures.

\section{Acknowledgements}

This paper is supported by Programs of China Geological Survey (DD20190705,DD20190511).

\section{References}

1. T.Yao, Application of high resolution remote sensing data in mine environment investigation [J]. Hebei Remote Sensing, 12-15(2015) 
2. M. Wen, B.B. Xue, QM. Yu, Analysis of the application of remote sensing technology in mine environmental monitoring [J]. Super Science, (03): 477-488(2011)

3. Jiangsu Province People's Government, http://www. jiangsu.gov.cn/col/col31359/index.html, 03/24 (2020)

4. W. Xu,Y. Zhou,HH. Tang, Shanghai overview 2019[M], Shanghai Lexicographical Publishing House,006(2019)

5. Regulation on remote sensing monitoring of mining exploration(DZ/0266-2014), Land and resources industry standard of the people's Republic of China (2014)

6. JZ. Yang, H.Wang, SF. Dong, etc. Remote sensing monitoring of mine geological environment in China(2016)[M].Beijing Geological Publishing House, 1-15(2018) 